\title{
Editorial
}

Pensar en Movimiento:

Revista de Ciencias del Ejercicio y la Salud ISSN 1659-4436

Vol. 16, No.2, pp. 1 - 3

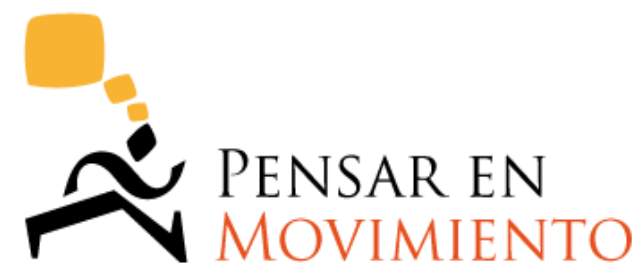

ReVISTA DE CIENCIAS DEl EJERCICIO Y LA SALUd

Abre el $1^{\circ}$ de julio, cierre al 31 de diciembre, 2018

\section{A FAVOR DE UN LENGUAJE INCLUSIVO NO EXHAUSTIVO}

\author{
Luis Fernando Aragón Vargas, Ph.D., FACSM \\ Director, PENSAR EN MOVIMIENTO \\ Publicado: 2018-12-24 \\ DOI 10.15517/pensarmov.v16i2.35761
}

Hace unos meses fue invitada la editora de la revista Pensar en Movimiento y fui invitado yo como su director a una capacitación sobre lenguaje inclusivo. Erróneamente, tuve la sensación de que se quería inculcar más bien lo que yo llamaría la lengua inclusiva, un lenguaje de género de naturaleza fuertemente feminista. Por alguna circunstancia no participé cuando se llevó a cabo el entrenamiento, pero la convocatoria me puso a reflexionar una vez más sobre esta confusa temática. Especialmente confusa y retante para alguien que, como yo, no es una persona estudiosa de la lengua, sino usuaria de esta. Varios comentarios sobre el tema en redes sociales no me permitieron olvidar el asunto.

La propuesta redentora de la utilización de terminología feminista ha logrado inmensas conquistas en las últimas décadas, aunque quizás a expensas de la elegancia y la practicalidad de la lengua. La iniciativa de dar una justa visibilidad a la mujer data, aproximadamente, de la mitad de la centuria pasada (quizás esa sea solamente la percepción mía, pues yo ingresé a la escuela primaria por esas fechas). Las ideas podrían escribirse casi completas usando terminología femenina, como en esta decena de frases, y aunque esa pareciera ser la meta de algunas personas, me parece más deseable la neutralidad o la inclusividad. Esa ha sido una preocupación permanente en mis tareas editoriales y comunicativas en general.

En su expresión más simple (y más utilizada), el lenguaje de género feminista consiste en incluir siempre a los y las en cada frase, lo cual ha generado más problemas que ventajas. En mis lecturas ocasionales al respecto ${ }^{1}$ y mi participación en actividades

\footnotetext{
${ }^{1}$ Enumero a continuación cuatro referencias seleccionadas con posiciones claramente distintas sobre el tema:
} 
académicas sobre múltiples temas, noto que hay mucho camino por recorrer. Existe una enorme distancia entre lo que se está discutiendo académicamente al respecto del lenguaje inclusivo, y lo que están haciendo demasiadas personas en la vida cotidiana, empantanadas en un lenguaje sexista feminista. Concepción Company, de la Academia Mexicana de la Lengua, opina que la gramática no es sexista ni deja de serlo; dice ella que eso depende de cómo construyamos el discurso, el cual podría ser más o ser menos inclusivo. Siguiendo su lógica, para mí es claramente sexista dirigirse a "los profesores y las profesoras", pues al anteponer a "los profesores", se deja la sensación de que "las profesoras" son un apéndice, una ocurrencia de último minuto. Me explican mis colegas que precisamente una de las metas del lenguaje inclusivo es evitar esos "los y las" a la vez que se evita la exclusión por omisión. Sin embargo, el uso defectuoso lo sigo escuchando en múltiples discursos de autoridades universitarias, así como de políticas y políticos, que además de hablar feo ni siquiera cumplen a cabalidad con la tarea de visibilizar a la mujer (pocas personas logran usar el "las y los" de manera exhaustiva; invito a quienes leen este editorial a realizar un conteo la próxima vez que escuchen un discurso). La solución escogida por algunas y algunos, a saber, el principio de "las damas primero", simplemente invierte la parcialidad. ¿No sería mejor usar lenguaje neutro, no marcado, siempre que fuera posible y acertado?

No puedo insistir suficiente en el tema: cuando la estrategia se limita a incluir masculino y femenino para buscar un equilibrio, los esfuerzos tienden a ser insuficientes, incompletos. Me permito seleccionar como ejemplo el formulario de consentimiento informado que propone el Comité Ético Científico de la Universidad de Costa Rica (versión junio 2017), el cual dice textualmente "Antes de dar su autorización debe hablar con el o la profesional responsable de la investigación o sus colaboradores sobre este estudio y ellos deben haber contestado satisfactoriamente todas sus preguntas (...)". Para cumplir cabalmente con el equilibrio entre femenino y masculino, debería escribirse "Antes de dar su autorización debe hablar con el o la profesional responsable de la investigación o sus colaboradores o colaboradoras sobre este estudio. Ella, él, ellos, ellas, o ellas y ellos, deben haber contestado (...)". Algunas personas señalan, acertadamente, que ese no es el camino correcto. Pero muchas otras siguen dando traspiés por esa vía.

Es que las cosas podrían llevarse demasiado lejos: si se insistiera únicamente en visibilizar a la mujer, no solamente se debería abogar por madurar algunas costumbres vigentes y aplicarlas bien. Podría insistirse en un lenguaje de género más claramente

Academia Mexicana de la Lengua (2018). Género y lenguaje. Descargado el 24/12/2018 de http://www.academia.org.mx/espin/respuestas/item/genero-y-lenguaje.

Centro de Investigación en Estudios de la Mujer CIEM-UCR (1992). Guía Breve Para el uso NO SEXISTA del lenguaje. Descargado el 24/12/2018 de https://cipacdh.org/pdf/guia breve lenguaje.pdf.

Fallas Alvarado, Cristian (2010). ¿Lenguaje inclusivo? Descargado el 24/12/2018 de http://agorahabla.com/noticias/villena/lenguaje-inclusivo.

Grijelmo, Álex (2018). No es sexista la lengua, sino su uso. Semanario Universidad (Costa Rica), 13 de marzo de 2018. Descargado el 24/12/2018 de https://semanariouniversidad.com/suplementos/no-es-sexista-lalengua-sino-su-uso/. 
feminista, promoviendo una reforma profunda en algunas disciplinas, como la química: así, no faltaría quien dijera que es una barbaridad que la plata $(\mathrm{Ag})$ esté solita entre todos los demás elementos de la tabla periódica (la cual, afortunadamente para esa causa, no se llama "el cuadro periódico"). También en la física y la cosmología, disciplinas en las cuales recientemente se introdujo el multiverso (?), podría haber omisión, pues no se habla-que yo sepa-de universas.

Mis divagaciones desembocaron en una pesadilla, en la cual algunas colegas llegaban al extremo de pedirme cambiarle el nombre a nuestra revista, pues el pensar (una acción de género masculino, si es que se puede decir así) no es exclusivo de los hombres, como tampoco lo debe ser el movimiento (también de género masculino). ¿Qué tal Reflexión Dinámica? Bueno, a pesar de que en mi pesadilla las modelas, las sobrecargas, las testigas y las sopranas estaban prontas a acompañar a la presidenta, la médica y la superintendenta, no todo estaba perdido.

Pero no logré despertarme. En mi pesadilla, colegas y colegos, yo percibía que como personas y personos serias y serios, honestas y honestos en estos planteamientos, debíamos ser más equilibrados y equilibradas, dejando a un lado los estereotipos y las estereotipas. Buscaba normas más claras, pero suficientemente sencillas. No queriendo ofender al hablar o al escribir, me sentía como un malabaristo, caminando por un campo minado. Como hombre, sentí que nos querían borrar de la sociedad: empecé a preguntarme si deberíamos comenzar a hablar de agresoras, no solamente de agresores. Claro, también referirnos a los víctimos y los terroristos, cuando procede. Pero elogiar además a los atletos por sus logros deportivos. Consultar algunos economistos en el proceso de toma de decisiones financieras. Maravillarnos ante los fenómenos del padre naturalezo, referirnos a Constantino Urcuyo como analisto político, a los músicos de Editus como artistos, a los jugadores del mundial de Rusia 2018 como futbolistos. Reconocer la labor del periodisto Ignacio Santos, del pediatro Carlos Sáenz Herrera, del pianisto Jacques Sagot... Cuando estaba a punto de destrozar mi lenguaje paterno, desperté sudando y a punto de caerme de la cama.

Me explican mis colegas más informadas del tema que en este, como en tantos otros asuntos, el péndulo se está devolviendo. Algunos especialistas han venido cuestionando las prácticas promovidas agresivamente a favor del lenguaje de género feminista, proponiendo la alternativa del lenguaje inclusivo, la cual celebro. Yo añoro aquellos tiempos en que, cuando se hablaba de todos, en neutro, se incluía a todas las personas; no era necesario decir "todos y todas". Tampoco era necesario referirse a "la totalidad de las personas presentes", como se ha sugerido. Podríamos dejar que "todo" incluya, efectivamente, todo. Algo tan sencillo no va a invisibilizar a las mujeres que tienen suficiente mérito propio.

Busquemos un sano equilibrio, sigamos esforzándonos por usar un lenguaje inclusivo no exhaustivo. $Y$ reconozcamos siempre el mérito de las personas, hombres o mujeres, cuando lo tienen. 